\title{
Assessment of regional crustal stability and its application to engineering geology in China
}

\begin{abstract}
The assessment and zonation of regional crustal stability is a discipline developed in recent years in China. It is aimed at providing necessary and sufficient information for the planning of urban construction, rational use of land and major engineering works. This paper presents in broad outline, the application of fundamental ideas and methods of assessment using the Yangtze River, Three Gorges Project on as an example.
\end{abstract}

\section{Introduction}

Earthquakes, volcanic eruptions, landslides, debris flows, etc. have often caused heavy economic losses and casualties and will continue to pose great threats to mankind (Barosh, 1987; Berry et al.. 1984: Qingxuan Chen et al., 1987). It is widely believed that these disastrous geological events generally occur in the tectonically weak zones of the earth's crust. Correct identification of these vulnerable zones and the temporal distribution of the hazardous events taking place along them, followed by corresponding precautionary countermeasures, will therefore greatly contribute to hazard reduction.

\section{Aims and methods}

Quantitative assessment of regional crustal stability has been attempted in recent years to replace the previous qualitative techniques (Qingxuan Chen. 1992; Haitao Hu et al., 1988; Guochang Liu. 1992). Tectonic stability analysis is at the the core of the new method and has a leading role in the assessment (Yunhui Shao et al., 1991; Chaoqun Yang, Ye Sun et al.. 1991). Usually, events in the relatively recent geological past are considered along with those of the present-day state in order to establish evolutionary trends.

The present tectonic activity in a region may be derived from data on the state of stress, and vertical and lateral movements of the earth's surface obtained from instrumental measurements such as insitu stress determinations (either by overcoring or hydrofracturing), repeated precise levelling, short baseline fault displacement surveys, microearthquake monitoring, etc. It is to be noted that the results of stress measurements can only represent the stress state at a few discrete points and it is necessary to incorporate them into a hypothetical stress field involving the whole region under study. This is achieved by material and mathematical modelling, in which the direction of loading and boundary conditions are determined from the results of the stress measurements, as well as the tectonic setting.

For the analysis of the tectonic activity in the geological past, it is usual to determine the change in elevation of some physiographic feature (e.g. a planation surface over a pre-existing fault). The history of movement on the fault is determined by geological methods. The palaeostress state can often be inferred from the orientation of such structural features as fold axis, thrust fault planes, cleavages, pressure solution effects (e.g. stylolites) joints, etc., which indicate the orientations of the principal stress axes, and from the strain effects in the crystal lattices of mineral grains, usually of calcite and quartz (e.g. dislocation gliding, mechanical twinning) which indicate their magnitudes. The palacostress study is used in comparison with the present stress state to obtain a picture of the history and evolution of the tectonic stresses in the region. Maps series can be produced to show the evolving stress and strain patterns as well as fault movements through time. If geophysical data on deep structures, are available, they will be used to reveal the relation between surface features and the structures at depth and tectonically unstable zones.

In the analysis of earthquake risk and microzonation of a region, it is necessary to identify potential seismic source zones of expected magnitudes as well as earthquake parameters. e.g. the annual earthquake frequency for a definite range of magnitude over a definite period of time and the b-values, and ground motion parameters. including attenuation of intensity. peak acceleration and response spectrum.

It is very useful, and important for practical purposes, to include the study of stability of surface slopes and foundations (rock and soil) in the overall appraisal of crustal stability in a region. Groundbased investigation of geomorphology. supplemented by remote sensing datat. is used to classify landform types and their relations to slope failure such as landslides, dehris llows, and collapse of weakened rock and soil brought about by quarrying. mining or groundwater erosion. Man-made hazards may be included, if necessary. A knowledge of the hydrogeological conditions is essential.

At major constuction sites, it is is necessary to tind out the distribution of highly fractured rock zones, incompetent horizons in bedrock, non-bearing soft clay layers, differentially weathered residual soils, and saturated loose fine sediments layers that might liquefy during shocks, and the burial conditions and engineering geologic characteristics of all of them. Geophysical exploration and drilling may have to be conducted in addition to hydrogeological and engineering geology mapping. Physical/mechanical properties of rocks and soils are determined both in the field and in the laboratory. In unstable areas, further microzonation on a much larger scale is sometimes needed.

\section{The Three Gorges Project}

A regional crustal stability assessment often precedes major engi neering works in China to ensure that foundations are stable and to forestall damage to major structures by seismic activity. Such assessments have been carried out for nuclear and hydraulic power stations in Guangdong (Haitao Hu et al., 1988) and Hubei provinces and the Ningxia Hui Autonomous Region. The Three Gorges Project on the Yangtze River may be cited as an example.

The Three Gorges Project is the largest of its kind and will have considerable social and economic benefits. A very full assessment of the stability of the dam site was therefore undertaken, proceeding first with the survey of a much larger area. about $300 \mathrm{~km}$ in diameter, around the dam site. After years of investigation the main results are as follows.

\section{Present-day tectonic activity}

The map constructed from the results of repeated precise levelling shows that the zero contour lines are located along the northern bank of the Yangtze River. They trend $\mathrm{E}-\mathrm{W}$, with negative values to the 
Table I Stability rating of the Three Gorges Dam region and its peripheral areas.

\begin{tabular}{|c|c|c|c|c|c|c|c|c|}
\hline \multirow{2}{*}{$\begin{array}{l}\text { The dam } \\
\text { region and } \\
\text { peripheral } \\
\text { areas } \\
\text { The dam } \\
\text { region }\end{array}$} & \multicolumn{4}{|c|}{ stable in order of decreasing stability from I to IV } & \multicolumn{2}{|c|}{ sub-stable } & relatively unstable & \multirow[t]{2}{*}{ unstable } \\
\hline & $\begin{array}{l}\text { stable } \\
\text { (I) }\end{array}$ & $\begin{array}{l}\text { stable } \\
\text { (II) }\end{array}$ & $\begin{array}{l}\text { stable } \\
\text { (III) }\end{array}$ & $\begin{array}{l}\text { stable } \\
\text { (IV) }\end{array}$ & sub-stable (I) & $\begin{array}{c}\text { sub-stable } \\
\text { (II) }\end{array}$ & $\begin{array}{l}\text { relatively } \\
\text { unstable } \\
\text { (I) }\end{array}$ & \\
\hline
\end{tabular}

Table 2 Factors and their weights assigned in the stability evaluation using fuzzy mathematics.

\begin{tabular}{rlc} 
No. & Factor & Weight $(\%)$ \\
\hline 1 & Intensity of future earthquakes & 13 \\
2 & Intensity of historical carthquakes & 13 \\
3 & Crustal deformation & 11 \\
4 & Fault displacement velocity & 11 \\
5 & Length of fault & 9 \\
6 & Concentration of strain energy & 9 \\
7 & Safety of fault & 8 \\
8 & Depth of fault penetration & 9 \\
9 & Age of faulting & 7 \\
10 & Physical state of rocks & 7 \\
11 & Development of exogenic geological & 4 \\
\hline
\end{tabular}

100

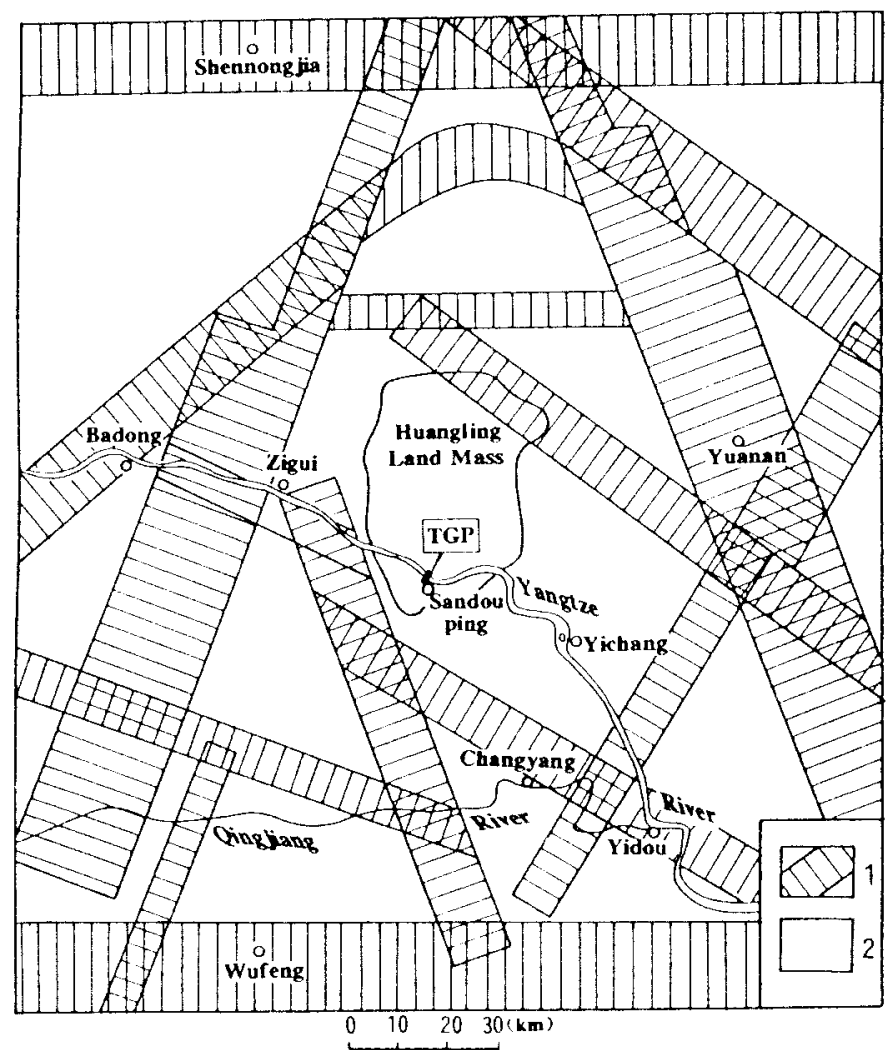

Figure I Sketch map showing tectonic stability zonation of the dam region.

1 Fault zone; 2 Blocks included in fault zones north and positive values to the south, suggesting a regional northward tilt estimated at $2 \mathrm{~mm} / 100 \mathrm{~km} / \mathrm{a}$. No significant change in elevation has been detected where the levelling traverses cross the faults. However, a short baseline survey across supposedly active faults gives a displacement of less than $0.07 \mathrm{~mm} / \mathrm{a}$.

In-situ stress measurements have yielded rather low values. A study of the stress field over a wide area obtained from numerical modelling compatible with the measured results shows that an earthquake with $M s>5$ seems unlikely in the dam region. When such studies are restricted only to the dam region, much smaller in areal extent, no earthquake greater than magnitude 3 is predicted.

It is also indicated that the present-day crustal movement is consistent with what has taken place in the near geological past and there has been a tendency for the intensity of activity to fall with time.

\section{Tectonic activity evolution}

Since the Yanshanian movement, the region has undergone mainly brittle deformation accompanied by warping and/or extensive uplifting. An investigation of the theoretical stress field during the Yanshanian, late Tertiary-Quaternary and the present time by numerical modelling. in combination with palaeostress determinations, indicates a gradual decrease in stress levels which is regarded as a sign of approaching stabilization of the region. The dam site lies in a lowstrain areä.

\section{Deep-seated structures}

It has been revealed by gravity and aeromagnetic survey as well as by artificial seismic sounding that the crust of the region is well divided into three layers with the lateral seismic wave velocities being relatively constant compared with other regions in China. The Moho is inclined to the west and the dam region is underlain by a late Precambrian crystalline basement just above the Moho slope. Most of the faults interpreted at depth do not penetrate the middle and upper crust to reach the surface.

\section{Earthquake risk analysis}

Earthquakes of magnitudes greater than 6 have been recorded at some distance from the dam site and only one shock of magnitude 5.1 has been reported in the dam region. It is estimated that the effects caused by future earthquakes, either near or distant, will not generally exceed an intensity of VI. Statistical analysis of the seismic frequency and magnitude gives $a=2.46$, and $b=0.75$, suggesting low levels of seismic activity. This is consistent with the deep structural setting, tectonic stability and low stress state of the region. Based on calculations of seismic risk probabilities versus acceleration of ground motion and the requirements of anti-seismic protection for large hydropower projects, an intensity of VII and a peak acceleration of $125 \mathrm{gal}$ for a probability of exceedence of 0.01 in 100 years are recommended for the design and construction of the dam. 


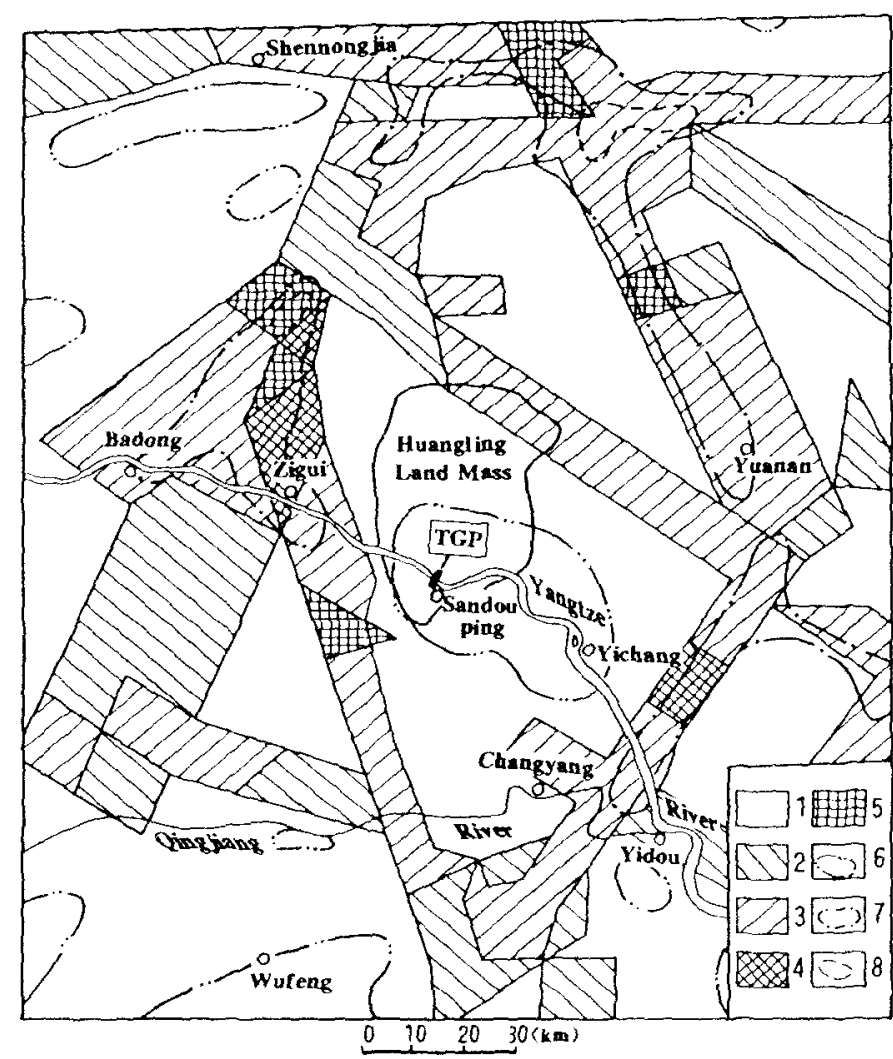

Figure 2 Crustal stability zonation of the dam region using fuzzy mathematics.

1 Stable area (I-III); 2 Stable area (IV); 3 Sub-stable area (I); 4 Sub-stable area (II); 5 Relatively unstable area (I); 6 High subordination (>0.85) area that is stable; 7 Low subordination (0.25) area that is substable; 8 Low subordination $(<0.15)$ area that is relatively less stable

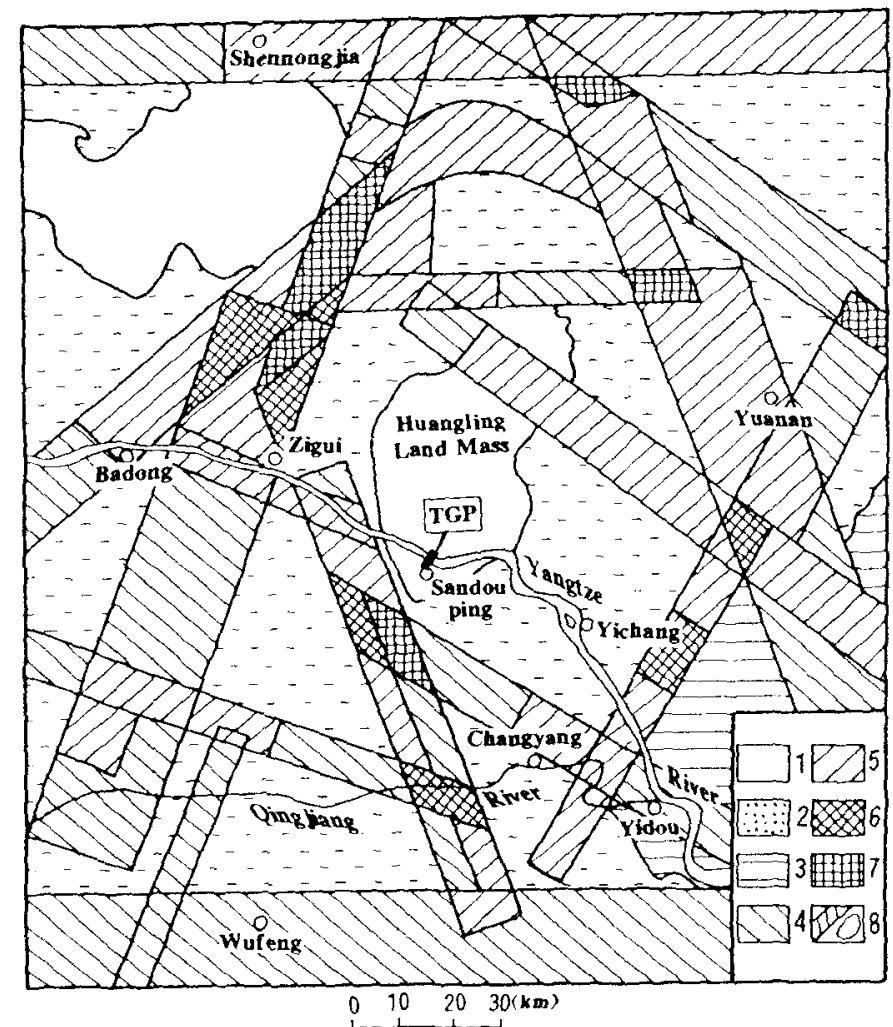

\section{Assessment and zonation of regional crustal stability}

The dam region and its peripheral areas ate rated as stable, sub-stable, relatively unstable and unstable as required by the engineering geology code of China, but the dam region itself is further rated as shown in Table 1.

The dam region was rated as relatively stable-stable after the first-made stability zonation for a wider expanse of country covering the dam site and surrounding areas. But for such an important major construction, this is evidently insufficient and a further meticulous assessment is essential. For this purpose, we have divided the region into 369 units on the basis of the tectonic stability zonation map (Figure 1) and the rock types that occur in the region to make a comprehensive crustal stability evaluation using fuzzy mathematics (Figure 2), in which eleven criteria ware chosen (Table 2). These play different roles in determining the stability of the region, and are accordingly given corresponding weights in the evaluation on a trial basis. The results are shown in Figure 3, from which it can be seen that the dam is located in a substantially stable rockmass.

\section{Concluding remarks}

The regional crustal stability assessment and zonation is aimed at providing necessary and sufficient information to users either for urban construction planning. land-use planning, or for construction of major engineering works. As the study has started and developed just in recent years, there is much to learn from the actual cases 10 improve the methodology and technology applied in appraisal. It is our sincere hope that more will be heard from the users.

\section{Acknowledgments}

The authors are grateful to Dr Shuren Wu and Dr Daogong Hu for their help and interest in this paper.

Figure 3 Sketch map showing a comprehensive crustal stability zonation of the dam region combining fuzzy mathematical evaluation with geological analysis.

1 stable area (I); 2 stable area $(I I) ; 3$ stable area $(I I I)$;

4 stable area (IV); 5 sub-stable area $(I) ; 6$ sub-stable area $(I I)$ within fault zone; 7 relatively unstable area (I) within fault zone; 8 Fault zone boundary. 


\section{References}

Barosh, P J, 1987, Earthquake Hazards in Eastern United States: Proceedings of Regional Crustal Stability and Geological Hazards, 1, China Daily Press, Beijing, China, pp.12-17.

Berry, M J, Anglin, F M, and Basham, P W, 1984, Earthquake Risk in Eastern Canada: International Symposium on Continental Seismicity and Earthquake Prediction, Seismological Press, Beijing, China, pp.774-775.

Qingxuan Chen, Ye Sun, Wenqu Zheng, 1987. Seismicity and Tentative Seismic Hazard Zonation of Beijing and Vicinity: Proceedings of Regional Crustal Stability and Geological Hazards, 1, China Daily Press, Beijing, China, pp.18-24.

Qingxuan Chen is a senior research geologist at the Institute of Geomechanics of the ChineseAcademy of Geological Sciences and an Academician of the Chinese Academy of Sciences. He was the leader of the IGCP Project 250 'Regional Crustal Stability and Geological Hazards' from 1986 to 1990. His research interests are in regional tectonics, geomechanics and geodynamics.
Qingxuan Chen, 1992, An Approach to Assessment of Regional Crustal Stability: Quaternary Sciences, no.4, Beijing, China.

Haitao Hu et al., 1988, Assessment and Analysis of Regional Crustal Stability for the Planning and Siting of Daya Bay Nuclear Power Plant, Guangdong Province: Archival Press, Beijing, China.

Guochang Liu, 1992, Regional Stability Engineering Geology: Jilin University Press, Changchun, China.

Yunhui Shao, Jinzhang Wu et al., 1991, A Study of Crustal Stability of Ningbo Region: Geological Publishing House, Beijing, China.

Chaoqun Yang, Ye Sun, Pude Shi, Xian Zhao et al., 1991, An Assessment of the Crustal Stability of Shenzhen Municipality: Geological Publishing House, Beijing, China.

Haitao $\mathbf{H u}$ is Honorary Director and senior research geologist at the Institute of Environmental Geology, Ministry of Geology and Mineral Resources. He is an Academician of the Chinese Academy of Engineering. His research concentrates on engineering geology.

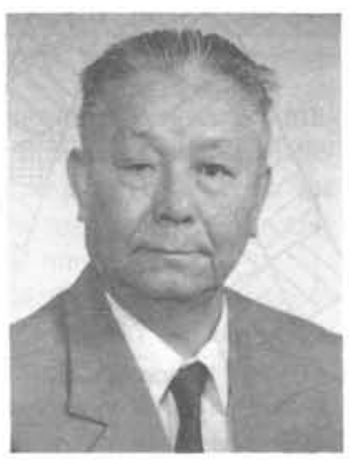

